\title{
INFLUÊNCIA DE SILICATO E CALCÁRIO NA NUTRIÇÃO, PRODUTIVIDADE E QUALIDADE DA BATATA SOB DEFICIÊNCIA HÍDRICA ${ }^{(1)}$
}

\author{
Adriano Luís Pulz ${ }^{(2)}$, Carlos Alexandre Costa Crusciol ${ }^{(3)}$, Leandro \\ Borges Lemos $^{(4)}$ \& Rogério Peres Soratto ${ }^{(5)}$
}

\begin{abstract}
RESUMO
A aplicação de silicato de Ca e Mg pode diminuir a acidez do solo e aumentar a disponibilidade de $\mathrm{Ca}, \mathrm{Mg}, \mathrm{P}$ e $\mathrm{Si}$ às plantas. $\mathrm{O} \mathrm{Si}$, mesmo não sendo essencial do ponto de vista fisiológico, traz inúmeros benefícios para o crescimento e o desenvolvimento vegetal, especialmente sob estresse. Este trabalho teve por objetivo avaliar a nutrição, a produtividade e a qualidade de tubérculos e batata cultivada em solo corrigido com calcário ou silicato sob dois níveis de umidade no solo. Os tratamentos foram constituídos pela aplicação de calcário dolomítico ou silicato de $\mathrm{Ca}$ e $\mathrm{Mg}$, visando elevar a saturação por bases do solo a $60 \%$, e por duas tensões de água no solo: 0,020 MPa (sem deficiência hídrica) e 0,050 MPa (com deficiência hídrica). $O$ experimento foi conduzido em casa de vegetação, em vasos contendo $50 \mathrm{~kg} \mathrm{dm}^{-3}$ de Latossolo Vermelho de textura média. O delineamento foi inteiramente ao acaso em fatorial 2 x 2, com oito repetições. A deficiência hídrica teve pouca influência na nutrição da batateira, porém reduziu a produção de tubérculos comercializáveis. O silicato de $\mathrm{Ca}$ e Mg proporcionou os mesmos níveis de correção do solo e de fornecimento desses nutrientes que o calcário dolomítico, além de maior disponibilidade de $\mathrm{P}$ e Si no solo e maior absorção desses elementos pelas plantas de batata, podendo ser utilizado em substituição ao calcário. $O$ fornecimento de Si à cultura da batata, mediante a aplicação de silicato, proporcionou maior altura de plantas, menor acamamento das hastes e maior produção de tubérculos comercializáveis.
\end{abstract}

Termos de indexação: Solanum tuberosum, silício, correção do solo, estresse hídrico, qualidade de tubérculos.

\footnotetext{
(1) Parte da Tese de Mestrado do primeiro autor, apresentada à Faculdade de Ciências Agronômicas, Universidade Estadual Paulista - FCA/UNESP. Campus de Botucatu (SP). Recebido para publicação em novembro de 2007 e aprovado em maio de 2008.

(2) Mestre em Agronomia (Agricultura), Faculdade de Ciências Agronômicas, Universidade Estadual Paulista - FCA/UNESP. Campus de Botucatu, Caixa Postal 237, CEP 18603-970 Botucatu (SP). E-mail: alpulz@yahoo.com.br

(3) Professor Adjunto do Departamento de Produção Vegetal, FCA/UNESP. Bolsista do CNPq. E-mail: crusciol@fca.unesp.br

(4) Professor Assistente Doutor do Departamento de Produção Vegetal, FCAV/UNESP, Campus de Jaboticabal, Via de Acesso Prof. Paulo Donato Castellane, s/no ${ }^{\circ}$ CEP 14884-900 Jaboticabal (SP). Bolsista do CNPq. E-mail: leandrobl@fcav.unesp.br

(5) Professor Assistente Doutor do Departamento de Produção Vegetal, FCA/UNESP. E-mail: soratto@fca.unesp.br
} 


\title{
SUMMARY: SILICATEANDLIMESTONE EFFECTS ONPOTATO NUTRITION, YIELD AND QUALITY UNDER DROUGHT STRESS
}

\begin{abstract}
$\mathrm{Ca}$ and $\mathrm{Mg}$ silicate application can ameliorate soil acidity and increase $\mathrm{Ca}, \mathrm{Mg}, \mathrm{P}$, and $\mathrm{Si}$ availability to plants. Although $\mathrm{Si}$ is not an essential nutrient, its application is beneficial for plant growth and development, mainly under stress conditions. This study aimed to evaluate potato nutrition, yield and quality of tuber in a soil amended with limestone and silicate, under two soil moisture conditions. The treatments consisted of dolomitic limestone or $\mathrm{Ca}$ and $\mathrm{Mg}$ silicate application, at rates calculated to raise the base saturation to $60 \%$, and at two soil water tensions: $0.020 \mathrm{MPa}$ (without drought stress) and $0.050 \mathrm{MPa}$ (drought stress). The experiment was carried out in a greenhouse in Botucatu, São Paulo, Brazil, in pots containing $50 \mathrm{~kg} \mathrm{dm}^{-3}$ of an Acrortox. A completely randomized design in a $2 \times 2$ factorial arrangement, with eight replications was used. Drought stress had little effect on potato nutrition, but decreased marketable tuber yield. Ca and $\mathrm{Mg}$ silicate reached the same levels of soil amelioration and Ca and $\mathrm{Mg}$ supply as dolomitic limestone, besides resulting in higher $P$ and $S i$ soil availability and plant uptake. Silicon supply through silicate application to potato induced higher plant height, reduced stem lodging, and higher marketable tuber yield.
\end{abstract}

Index terms: Solanum tuberosum, silicon, soil amelioration, water deficit, tuber quality.

\section{INTRODUÇÃO}

A eficiência produtiva da cultura da batata (Solanum tuberosum L.) garante elevado aproveitamento de áreas destinadas à produção de alimentos, característica importante num cenário mundial de constante crescimento populacional. Contudo, essa cultura é muito sensível à deficiência hídrica (Loon, 1981; Costa et al., 1997). Essa sensibilidade é atribuída ao seu sistema radicular pequeno e pouco profundo, o que torna a planta pouco eficiente na absorção de água (Gregory \& Simmonds, 1992). Curtos períodos de deficiência hídrica podem resultar em menor crescimento, baixas produtividade e qualidade dos tubérculos (Costa et al., 1997; Erdem et al., 2006). A deficiência hídrica nos estádios de crescimento vegetativo e iniciação dos tubérculos causa redução no número de tubérculos e, no estádio de tuberização, acentua a redução do tamanho deles (Loon, 1981; Costa et al., 1997).

Com relação ao fornecimento de água à cultura da batata, Epstein \& Grant (1973) verificaram maior produtividade com a tensão de água no solo entre 0,020 e 0,030 MPa. Ekanayake (1994) relata que se deve realizar irrigação na cultura da batata, quando os valores de tensão de água no solo estão entre 0,030 e 0,040 MPa. Já Oliveira \& Valadão (1997) consideram $0,020 \mathrm{MPa}$ como o valor correspondente a uma condição hídrica adequada e 0,050 MPa à tensão que provoca declínio na produtividade.

Na cultura da batata, a calagem é realizada principalmente para fornecer $\mathrm{Ca}$, pois o teor desse nutriente no solo está positivamente relacionado à produtividade e à qualidade dos tubérculos (Miranda Filho et al., 1990). Assim, a recomendação no Estado de São Paulo visa elevar a saturação por bases a $60 \%$ e o teor de $\mathrm{Mg}$ ao mínimo de $8 \mathrm{mmol}_{\mathrm{c}} \mathrm{dm}^{-3}$. Para cultivares mais exigentes em $\mathrm{Ca}$, recomenda-se complementação com fontes mais solúveis (Lorenzi et al., 1997).

A aplicação de silicatos de Ca e Mg diminui a acidez do solo (Carvalho-Pupatto et al., 2004; Ramos et al., 2006; Camargo et al., 2007), devido à presença de agente neutralizante da acidez, como o $\mathrm{SiO}_{3}{ }^{2-}$ (Alcarde, 1992), aumenta a disponibilidade de $\mathrm{Ca}, \mathrm{Mg}$ (CarvalhoPupatto et al., 2004; Ramos et al., 2006) e P (Prado \& Fernandes, 2001); aumenta o teor de Si no solo (Carvalho-Pupatto et al., 2004; Ramos et al., 2006; Camargo et al., 2007), refletindo em aumento da produtividade de culturas que acumulam esse elemento, como é o caso do arroz (Carvalho-Pupatto et al., 2004). Assim, estudos têm demonstrado que os silicatos de $\mathrm{Ca}$ e $\mathrm{Mg}$ podem ser utilizados como corretivos da acidez do solo e como fonte de Si (CarvalhoPupatto et al., 2004; Ramos et al., 2006).

O Si não é considerado elemento essencial para o crescimento das plantas, mas tem tido efeitos benéficos em várias espécies (Ma, 2004); proporciona efetivo controle de doenças em plantas (Guével et al., 2007) e tem sido relacionado à redução de efeitos prejudiciais decorrentes de agentes químicos (salinidade, toxidez causada por metal pesado, desbalanço de nutrientes) e físicos (acamamento, seca, radiação, alta e baixa temperaturas) (Zhu et al., 2004; Ma \& Yamaji, 2006). Muitos desses efeitos benéficos são atribuídos à sua deposição nas paredes celulares de vários órgãos das plantas, além de outros mecanismos (Ma, 2004; Ma \& Yamaji, 2006).

Com relação à deficiência hídrica, o efeito benéfico do Si tem sido associado ao aumento da capacidade de defesa antioxidante (Gong et al., 2005; Zhu et al., 2005) e à manutenção da taxa fotossintética, da condutância 
estomática da planta, mesmo em solo seco (Hattori et al., 2005), devido à redução da transpiração através da cutícula (Ma \& Yamaji, 2006).

Como os silicatos de $\mathrm{Ca}$ e $\mathrm{Mg}$ podem ser utilizados para a correção da acidez do solo e o fornecimento de $\mathrm{Ca}, \mathrm{Mg}$ e $\mathrm{Si}$ às culturas, e sendo o Si um elemento que pode conferir tolerância à deficiência hídrica, seu uso pode ser alternativa para obtenção de maior produtividade e melhor qualidade dos tubérculos, além de poder reduzir o custo de produção da cultura da batata.

Este trabalho teve por objetivo avaliar a nutrição, a produtividade e a qualidade de tubérculos de batata cultivada em solo corrigido com calcário dolomítico ou silicato de $\mathrm{Ca}$ e $\mathrm{Mg}$ sob dois níveis de umidade no solo.

\section{MATERIAL E MÉTODOS}

O experimento foi conduzido em casa de vegetação pertencente à Faculdade de Ciências Agronômicas UNESP, Município de Botucatu, $\operatorname{SP}\left(48^{\circ} 23^{\prime} \mathrm{W}\right.$ e $22^{\circ}$ 51 ' S; $765 \mathrm{~m}$ de altitude), em vasos com dimensões de 40 x 40 x $35 \mathrm{~cm}$, contendo $50 \mathrm{~kg} \mathrm{dm}^{-3}$ de Latossolo Vermelho distroférrico (Embrapa, 2006). As características químicas (Raij et al., 2001) e granulométricas (Embrapa, 1997) do solo foram determinadas antes da instalação do experimento, cujos resultados foram: $\mathrm{MO}: 21,0 \mathrm{~g} \mathrm{dm}^{-3} ; \mathrm{pH}\left(\mathrm{CaCl}_{2}\right)$ : 4,0; P (resina): $2,1 \mathrm{mg} \mathrm{dm}{ }^{-3} ; \mathrm{K}^{+}, \mathrm{Ca}^{2+}, \mathrm{Mg}^{2+} \mathrm{e} \mathrm{H}+\mathrm{Al}:$ $0,1,6,0,0,8$ e $78,1 \mathrm{mmol}_{\mathrm{c}} \mathrm{dm}^{-3}$, respectivamente; e saturação por bases: $8,1 \%$. Os teores de areia, silte e argila foram, respectivamente, de 630, 40 e $330 \mathrm{~g} \mathrm{~kg}^{-1}$.

$\mathrm{O}$ delineamento experimental foi inteiramente casualizado, em esquema fatorial $2 \times 2$, com oito repetições. Os tratamentos foram constituídos pela aplicação de calcário dolomítico ou silicato de $\mathrm{Ca}$ e $\mathrm{Mg}$ (Quadro 1), visando elevar a saturação por bases do solo a 60 \% (Lorenzi et al., 1997), e por duas tensões de água no solo: 0,020 MPa (sem deficiência hídrica) e 0,050 MPa (com deficiência hídrica).

Foram adicionados $150 \mathrm{mg} \mathrm{dm}^{-3} \mathrm{de} \mathrm{P}$ (superfosfato simples, $\left.18 \% \mathrm{P}_{2} \mathrm{O}_{5}\right), 150 \mathrm{mg} \mathrm{dm}^{-3}$ de $\mathrm{K}(\mathrm{KCl}, 60 \%$ $\mathrm{K}_{2} \mathrm{O}$ ) e $5,0,1,0,0,4,1,7,1,1$ e $0,06 \mathrm{mg} \mathrm{dm}^{-3} \mathrm{de} \mathrm{Zn,} \mathrm{B,}$ $\mathrm{Cu}, \mathrm{Fe}, \mathrm{Mn}$ e Mo, respectivamente (FTE BR-12, 9,0 \% de $\mathrm{Zn} ; 1,8 \%$ de $\mathrm{B} ; 0,8 \%$ de $\mathrm{Cu} ; 3,0 \%$ de Fe; $2,0 \%$ de Mn; e $0,1 \%$ de Mo). Posteriormente, o solo foi incubado por 40 dias.

Antes do plantio, o solo foi tratado com carbofuran (87,5 mg/vaso do a.i.). Em 15/09/2005, plantou-se um tubérculo-semente do cv. Bintje, com 30 a $50 \mathrm{~mm}$ de diâmetro e com brotações vigorosas, por vaso, a $15 \mathrm{~cm}$ de profundidade. A emergência ocorreu aos 9 dias após o plantio (DAP).

$\mathrm{O}$ fornecimento de $\mathrm{N}$ foi parcelado em três aplicações aos 4, 14 e 25 dias após a emergência (DAE),
Quadro 1. Características químicas e doses dos corretivos e de Si utilizadas no experimento

\begin{tabular}{|c|c|c|}
\hline Característica & $\begin{array}{c}\text { Calcário } \\
\text { dolom ítico }\end{array}$ & $\begin{array}{c}\text { Silicato } \\
\text { de Ca e Mg }\end{array}$ \\
\hline $\mathrm{SiO}_{2}, \mathrm{~g} \mathrm{~kg}^{-1}$ & - & 227 \\
\hline $\mathrm{CaO}, \mathrm{g} \mathrm{kg}^{-1}$ & 390 & 420 \\
\hline $\mathrm{MgO}, \mathrm{g} \mathrm{kg}^{-1}$ & 130 & 120 \\
\hline $\mathrm{P}_{2} \mathrm{O}_{5}, \mathrm{~g} \mathrm{~kg}^{-1}$ & 0,4 & 4,2 \\
\hline $\mathrm{K}_{2} \mathrm{O}, \mathrm{g} \mathrm{kg}-1$ & 1,7 & 2,0 \\
\hline $\mathrm{SO}_{3}, \mathrm{~g} \mathrm{kg-1}$ & - & 3,7 \\
\hline $\mathrm{Fe}_{2} \mathrm{O}_{3}, \mathrm{~g} \mathrm{~kg}^{-1}$ & - & 110 \\
\hline $\mathrm{MnO}, \mathrm{g} \mathrm{kg}^{-1}$ & - & 18 \\
\hline PRNT, \% & 90 & 82 \\
\hline Dose do corretivo, $\mathrm{g} \mathrm{dm}^{-3}$ & 2,45 & 2,68 \\
\hline Dose de $\mathrm{Si}, \mathrm{mg} \mathrm{dm}^{-3}$ & - & 284,4 \\
\hline
\end{tabular}

nas quantidades de $44,17,6$ e $14 \mathrm{mg} \mathrm{dm}^{-3}$ de $\mathrm{N}$, respectivamente, utilizando uréia.

O potencial de água no solo foi controlado por meio de tensiômetros de $\mathrm{Hg}$ instalados no dia do plantio a $15 \mathrm{~cm}$ de profundidade. Após a emergência das plantas e antes do estabelecimento dos tratamentos de deficiência hídrica, as irrigações foram realizadas quando a tensão média de água no solo atingiu $0,020 \mathrm{MPa}$. Os tratamentos com as tensões de 0,020 e 0,050 MPa de água no solo foram estabelecidos aos $10 \mathrm{DAE}$ e mantidos até $60 \mathrm{DAE}$, sendo os valores definidos de acordo com as recomendações de Oliveira \& Valadão (1997) e conforme a curva da capacidade de retenção de água do solo. Essa curva foi determinada em laboratório, segundo método de placas de pressão recomendado por Richards (1949) e Topp et al. (1993). As irrigações foram realizadas manualmente e calculadas de modo a elevar os valores de tensão aos da capacidade de campo para todos os tratamentos, quando as tensões estabelecidas (tratamentos) foram atingidas. As lâminas totais médias aplicadas foram de 392 e $323 \mathrm{~mm}$, respectivamente, nos tratamentos sem $(-0,020 \mathrm{MPa})$ e com $(-0,050 \mathrm{MPa})$ deficiência hídrica.

Foram realizados tratamentos fitossanitários preventivos, quando as condições climáticas eram favoráveis à ocorrência de doenças e pragas. Para o controle de doenças, foram utilizados os fungicidas azoxytrobin nos dias 1/10, 12/10, 2/11, 14/11 e 23/11/ 2005; cimoxanil + mancozebe nos dias 5/10, 12/10 e 23/11/2005; e mancozebe nos dias 21/10, 2/11 e 14/11/ 2005. Para o controle de pragas, foram usados os inseticidas paration-metílico nos dias 1/10, 2/11 e 19/ 11/2005 e clorpirifós nos dias 5/10, 21/10 e 14/11/2005. Todos os produtos foram utilizados nas doses recomendadas para a cultura.

Aos 40 DAE, foram coletadas duas folhas (terceiras folhas expandidas a partir do ápice da planta) de cada 
unidade experimental, para a realização da diagnose foliar. As folhas foram secas em estufa a $65^{\circ} \mathrm{C}$ por $72 \mathrm{~h}$. Em seguida, foram moídas para posterior determinação dos teores de $\mathrm{N}, \mathrm{P}, \mathrm{K}, \mathrm{Ca}, \mathrm{Mg}, \mathrm{S}, \mathrm{B}, \mathrm{Cu}$, $\mathrm{Fe}, \mathrm{Mn}$ e Zn, segundo Malavolta et al. (1997), e de Si, segundo Korndörfer et al. (2004).

Aos 60 DAE, foram determinados altura da planta, número de hastes por planta e acamamento das hastes. A altura da planta foi determinada medindose o comprimento da haste principal de cada unidade experimental. $\mathrm{O}$ acamamento das hastes foi avaliado por meio da relação entre o número de hastes acamadas (hastes que tocavam o solo) e o número total de hastes, sendo o resultado expresso em percentagem.

O ciclo da cultura teve duração de 87 dias, considerando seu término quando $80 \%$ das plantas apresentavam amarelecimento das hastes. Dez dias após a seca total das hastes, os tubérculos foram separados do solo, escovados e, posteriormente, foi feita a classificação pelo diâmetro transversal, sendo considerados comercializáveis aqueles com diâmetro acima de $23 \mathrm{~mm}$. Os tubérculos foram contados e pesados.

Para a determinação do teor de matéria seca, os tubérculos foram fatiados, pesados e colocados em estufa de circulação forçada a $70{ }^{\circ} \mathrm{C}$ até massa em equilíbrio. Posteriormente, mediante a relação entre a matéria seca e úmida, foi obtido o teor de matéria seca, em porcentagem.

Os tubérculos utilizados para a determinação da matéria seca foram moídos, e o material foi utilizado para obtenção do teor de Si (Korndörfer et al., 2004).

Após a colheita, o solo de cada vaso foi amostrado, seco e submetido à determinação de $\mathrm{pH}\left(\mathrm{CaCl}_{2}\right), \mathrm{P}$,

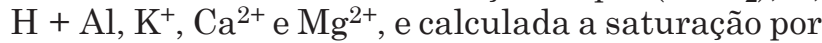
bases (Raij et al., 2001) e o teor de Si solúvel, usando solução de $\mathrm{CaCl}_{2}$ 0,01 mol L-1 (Korndörfer et al., 2004). Os resultados foram submetidos à análise de variância e as médias dos tratamentos foram comparadas pelo teste t(DMS), a $5 \%$.

\section{RESULTADOS E DISCUSSÃO}

Mediante a análise do solo realizada em cada uma das parcelas, após a colheita das plantas, verificou-se que o teor de $\mathrm{P}$ disponível foi influenciado pelo corretivo utilizado, e a aplicação de silicato proporcionou maior teor do nutriente (Quadro 2). Prado \& Fernandes (2001) também verificaram maior teor de $\mathrm{P}$ disponível no solo corrigido com silicato em comparação com calcário. Os ânions de silicatos exercem competição com o P pelos mesmos sítios de adsorção (Smyth \& Sanchez, 1980). Esses sítios de P são saturados ou bloqueados pelo ânion silicato (Lopes, 1977), aumentando a eficiência da adubação fosfatada. $\mathrm{O}$ maior teor de $\mathrm{P}_{2} \mathrm{O}_{5}$ no silicato, em comparação com o calcário (Quadro 1), também pode ter tido pequena contribuição para o aumento do teor de P no solo.

Os corretivos aplicados elevaram os teores de $\mathrm{Ca}^{2+}$ e $\mathrm{Mg}^{2+}$ e a saturação por bases do solo em relação à análise inicial do solo (Quadro 2). Os baixos valores de $\mathrm{pH}$ e V \% estavam relacionados à acidificação e extração de nutrientes do meio em função do cultivo em ambiente confinado.

Com relação ao Si no solo, observou-se que os teores foram maiores no tratamento com silicato (Quadro 3), nas duas tensões de água estudadas, e que, para o tratamento com calcário, o teor de Si foi maior na menor tensão de água $(0,020 \mathrm{MPa})$. Entre as fontes de Si solúvel no solo, estão a decomposição de resíduos vegetais e a dissociação do ácido silícico polimérico (Lima Filho et al., 1999), ambos os processos favorecidos pela da água. O teor mais elevado de $\mathrm{Si}$ solúvel no tratamento de menor tensão $(0,020 \mathrm{MPa})$ pode ser resultante desses processos, que foram

Quadro 2. Características químicas do solo, após a colheita da batata, em função da tensão de água no solo e de corretivos

\begin{tabular}{|c|c|c|c|c|c|c|c|c|}
\hline Tratamento & $\mathrm{pH}(\mathrm{CaCl2})$ & $\mathbf{P}$ & $\mathbf{H}+\mathbf{A l}$ & $\mathbf{K}$ & $\mathbf{C a}$ & $\mathbf{M g}$ & $\mathbf{V}$ & Si \\
\hline Tensão de água no solo (T) & & $\mathrm{mg} \mathrm{dm} \mathrm{m}^{-3}$ & $\longrightarrow$ & \multicolumn{3}{|c|}{$\mathrm{mmol}_{\mathrm{c}} \mathrm{dm}^{-3}$} & $\%$ & $\mathrm{mg} \mathrm{dm} \mathrm{m}^{-3}$ \\
\hline $0,020 \mathrm{MPa}$ & $4,4 \mathrm{a}$ & $61,1 \mathrm{a}$ & $55,6 \mathrm{a}$ & $2,7 \mathrm{a}$ & $29,7 \mathrm{a}$ & $6,2 \mathrm{a}$ & $40,8 \mathrm{a}$ & 3,1 \\
\hline $0,050 \mathrm{MPa}$ & $4,4 \mathrm{a}$ & $61,2 \mathrm{a}$ & $56,9 \mathrm{a}$ & $2,8 \mathrm{a}$ & $27,2 \mathrm{a}$ & $5,6 \mathrm{a}$ & $38,4 \mathrm{a}$ & 2,6 \\
\hline \multicolumn{9}{|l|}{ Corretivo (C) } \\
\hline Calcário & $4,5 \mathrm{a}$ & $43,9 \mathrm{~b}$ & $55,1 \mathrm{a}$ & $2,7 \mathrm{a}$ & $27,0 \mathrm{a}$ & $5,7 \mathrm{a}$ & $39,0 \mathrm{a}$ & 2,4 \\
\hline Silicato & $4,4 \mathrm{a}$ & $78,4 \mathrm{a}$ & $57,4 \mathrm{a}$ & $2,8 \mathrm{a}$ & $29,9 \mathrm{a}$ & $6,1 \mathrm{a}$ & $40,1 \mathrm{a}$ & 3,3 \\
\hline Interação T x C & $\mathrm{ns}$ & $\mathrm{ns}$ & $\mathrm{ns}$ & $\mathrm{ns}$ & $\mathrm{ns}$ & $\mathrm{ns}$ & $\mathrm{ns}$ & * \\
\hline CV (\%) & 3,7 & 15,0 & 12,0 & 23,9 & 29,2 & 30,4 & 22,4 & 11,4 \\
\hline
\end{tabular}

Médias seguidas de letras distintas na coluna, para cada fator, diferem entre si pelo teste t (DMS) a 5 \%. Interação: ns: não significativo $\mathrm{e}^{*}$ : significativo, pelo teste $\mathrm{t}$ a $5 \%$. 
favorecidos pela maior disponibilidade de água, hipótese que é reforçada pelo fato de a diferença entre os teores de Si no solo, em função da disponibilidade de água, ter ocorrido somente no tratamento com calcário, no qual a disponibilidade do elemento era mais baixa, assim a solubilização do Si pela maior disponibilidade hídrica foi destacada.

Com relação à nutrição das plantas, verificou-se que houve efeito do corretivo utilizado no teor de $\mathrm{N}$ nas folhas, sendo maior o teor no tratamento com calcário (Quadro 4). O menor teor no tratamento que recebeu silicato pode ser devido à diluição, já que as plantas deste tratamento apresentaram maior altura, provavelmente em função de maior alongamento celular. Os teores de $\mathrm{N}$ observados estão pouco acima da faixa considerada adequada (40 a $\left.50 \mathrm{~g} \mathrm{~kg}^{-1}\right)$ por Lorenzi et al. (1997), indicando que não houve falta do nutriente para as plantas.

$\mathrm{O}$ maior teor de $\mathrm{P}$ nas folhas no tratamento com silicato, em relação ao calcário, pode ser devido à maior disponibilidade de $\mathrm{P}$ no solo, verificado no tratamento

Quadro 3. Teor de Si no solo, após a colheita da batata, em função da tensão de água do solo e de corretivos

\begin{tabular}{|c|c|c|}
\hline \multirow{2}{*}{$\begin{array}{l}\text { Tensão de água } \\
\text { no solo }\end{array}$} & \multicolumn{2}{|c|}{ Corretivo } \\
\hline & Calcário & Silicato \\
\hline & \multicolumn{2}{|c|}{$-\mathrm{mg} \mathrm{dm}{ }^{-3}$} \\
\hline $0,020 \mathrm{MPa}$ & $2,9 \mathrm{aB}$ & $3,4 \mathrm{aA}$ \\
\hline $0,050 \mathrm{MPa}$ & $1,9 \mathrm{bB}$ & $3,2 \mathrm{aA}$ \\
\hline
\end{tabular}

Médias seguidas de letras distintas, minúsculas nas colunas e maiúsculas nas linhas, diferem entre si pelo teste de t (DMS) a $5 \%$. com silicato (Quadros 2 e 4), o que pode ser explicado pela desorção de $\mathrm{P}$ promovida pela presença de $\mathrm{Si}$ solúvel, aumentando sua disponibilidade (Prado \& Fernandes, 2001) e, conseqüentemente, a absorção do elemento pelas plantas. Os teores de P estão dentro da faixa adequada (Lorenzi et al., 1997), exceto no tratamento com deficiência hídrica $(-0,050 \mathrm{MPa})$ e com silicato, que apresentaram valores superiores.

Os teores de $\mathrm{Ke}$ Ca não foram influenciados pelos tratamentos (Quadro 4). Lorenzi et al. (1997) relataram que a faixa adequada de teores foliares de K para a batateira está entre 40 e $65 \mathrm{~g} \mathrm{~kg}^{-1}$, na qual se enquadram os teores obtidos em todos os tratamentos. Quanto ao Ca, os teores encontrados estão de acordo com os considerados adequados por Jones Junior et al. (1991), entretanto abaixo do adequado para Lorenzi et al. (1997). Não foram observados sintomas de deficiência nas plantas ou sinal de insuficiência desse nutriente na produção de tubérculos.

$\mathrm{O}$ teor de $\mathrm{Mg}$ foi maior nas folhas das plantas cultivadas em solo corrigido com silicato (Quadro 4). Isso pode ser devido ao menor PRNT do silicato utilizado, o que ocasionou a aplicação de quantidade pouco maior do silicato para obtenção do mesmo nível de correção do solo em relação ao calcário (Quadro 1). Essa maior quantidade aplicada pode ter proporcionado maior disponibilidade e absorção do nutriente pelas plantas (Quadro 2). Apenas no tratamento com silicato, os teores de $\mathrm{Mg}$ nas folhas estavam na faixa preconizada por Lorenzi et al. (1997) como adequada para a cultura da batata. Nos demais tratamentos, os teores encontravam-se abaixo dessa faixa.

O teor de S nas folhas não foram influenciados pelos tratamentos e se encontravam acima da faixa (2,5 a $5,0 \mathrm{~kg} \mathrm{~g}^{-1}$ ) considerada adequada (Lorenzi et al., 1997).

Os teores de B, Cu, Fe e Zn não foram influenciados pelos fatores estudados (Quadro 4). Houve efeito da interação entre os fatores no teor de Mn (Quadro 5).

Quadro 4. Teores de N, P, K, Ca, Mg, S, B, Cu, Fe, Mn, Zn e Si nas folhas de plantas de batata em função da tensão de água no solo e de corretivos

\begin{tabular}{|c|c|c|c|c|c|c|c|c|c|c|c|c|}
\hline Tratamento & $\mathbf{N}$ & $\mathbf{P}$ & $\mathbf{K}$ & $\mathbf{C a}$ & Mg & S & B & $\mathrm{Cu}$ & $\mathrm{Fe}$ & Mn & $\mathrm{Zn}$ & $\mathrm{Si}$ \\
\hline Tensão de água no solo (T) & \multicolumn{6}{|c|}{$\longrightarrow \mathrm{g} \mathrm{kg}^{-1}$} & \multicolumn{6}{|c|}{$-\mathrm{mg} \mathrm{kg}^{-1}$} \\
\hline $0,020 \mathrm{MPa}$ & $51,8 \mathrm{a}$ & $5,0 \mathrm{a}$ & $41,6 \mathrm{a}$ & $7,8 \mathrm{a}$ & $2,9 \mathrm{a}$ & $6,9 \mathrm{a}$ & $12,3 \mathrm{a}$ & $19,7 \mathrm{a}$ & $149,9 \mathrm{a}$ & 119,6 & $62,2 \mathrm{a}$ & 0,39 \\
\hline $0,050 \mathrm{MPa}$ & $52,7 \mathrm{a}$ & $5,6 \mathrm{a}$ & $41,8 \mathrm{a}$ & $7,9 \mathrm{a}$ & $2,8 \mathrm{a}$ & $7,5 \mathrm{a}$ & $12,9 \mathrm{a}$ & $18,9 \mathrm{a}$ & $152,0 \mathrm{a}$ & 122,5 & $58,8 \mathrm{a}$ & 0,43 \\
\hline \multicolumn{13}{|l|}{ Corretivo (C) } \\
\hline Calcário & $53,8 \mathrm{a}$ & $4,7 \mathrm{~b}$ & $43,5 \mathrm{a}$ & $7,7 \mathrm{a}$ & $2,7 \mathrm{~b}$ & $7,3 \mathrm{a}$ & $12,6 \mathrm{a}$ & $20,8 \mathrm{a}$ & $153,9 \mathrm{a}$ & 85,9 & $59,9 a$ & 0,39 \\
\hline Silicato & $50,8 \mathrm{~b}$ & $5,8 \mathrm{a}$ & $39,9 \mathrm{a}$ & $7,9 \mathrm{a}$ & $3,0 \mathrm{a}$ & $7,2 \mathrm{a}$ & $12,6 \mathrm{a}$ & $17,8 \mathrm{a}$ & $148,0 \mathrm{a}$ & 156,3 & $61,1 \mathrm{a}$ & 0,44 \\
\hline Interação T $\times \mathrm{C}$ & $\mathrm{ns}$ & $\mathrm{ns}$ & $\mathrm{ns}$ & $\mathrm{ns}$ & $\mathrm{ns}$ & $\mathrm{ns}$ & $\mathrm{ns}$ & $\mathrm{ns}$ & $\mathrm{ns}$ & $*$ & $\mathrm{~ns}$ & * \\
\hline CV (\%) & 6,5 & 24,1 & 13,9 & 10,1 & 13,7 & 14,6 & 12,2 & 28,1 & 15,7 & 26,7 & 18,7 & 12,0 \\
\hline
\end{tabular}

Médias seguidas de letras distintas na coluna, para cada fator, diferem entre si pelo teste t (DMS) a $5 \%$. Interação: ns: não significativo e *: significativo, pelo teste t a $5 \%$. 
Quadro 5. Concentração de Mn e Si nas folhas de plantas de batata em função da tensão de água do solo e de corretivos

\begin{tabular}{ll}
\hline Tensão de água no solo & \multicolumn{2}{c}{ Corretivo } \\
\cline { 2 - 2 } & Calcário $\quad$ Silicato \\
\hline
\end{tabular}

\begin{tabular}{cccc} 
& & \multicolumn{3}{c}{$\mathrm{Mn}, \mathrm{mg} \mathrm{kg}$} \\
0,020 & $\mathrm{MPa}$ & $81,3 \mathrm{aB}$ & $158,0 \mathrm{aA}$ \\
0,050 & $\mathrm{MPa}$ & $90,5 \mathrm{aA}$ & $154,5 \mathrm{aA}$ \\
& & \multicolumn{2}{c}{$\mathrm{Si}, \%$} \\
0,020 & $\mathrm{MPa}$ & $0,37 \mathrm{aA}$ & $0,42 \mathrm{bA}$ \\
0,050 & $\mathrm{MPa}$ & $0,41 \mathrm{aB}$ & $0,47 \mathrm{aA}$
\end{tabular}

Médias seguidas de letras distintas, minúsculas nas colunas e maiúsculas nas linhas, diferem entre si pelo teste de t (DMS) a $5 \%$.

O maior teor do elemento, observado no tratamento com silicato, na menor tensão $(0,020 \mathrm{MPa})$, em relação ao tratamento com calcário, é contrário aos resultados obtidos por Vermas \& Minhas (1989), que constataram diminuição dos teores de Mn em plantas de arroz cultivadas em meio com Si. Eles atribuíram essa redução ao acúmulo desses micronutrientes nas raízes e à conseqüente redução na translocação para a parte aérea das plantas. Entretanto, o silicato utilizado continha na sua composição 1,8 \% de MnO (Quadro 1), o que pode ter ocasionado maior disponibilidade do elemento no solo e assim maior absorção pelas plantas.

Segundo Lorenzi et al. (1997), os teores adequados de micronutrientes nas folhas da batateira são: 25 a 50,7 a 20, 50 a 100,30 a 250 e 20 a 60 mg kg-1, para $\mathrm{B}, \mathrm{Cu}, \mathrm{Fe}, \mathrm{Mn}$ e $\mathrm{Zn}$, respectivamente. Assim, constata-se que os teores de B e Fe estavam abaixo e acima das faixas adequadas, respectivamente, e que os de $\mathrm{Cu}, \mathrm{Mn}$ e Zn estavam adequados.

O teor de Si foi alterados pela interação entre corretivo e tensão de água no solo (Quadro 5). Constata-se que, apenas sob deficiência hídrica (-0,050 $\mathrm{MPa})$, a aplicação de silicato proporcionou maior teor de Si nas folhas das plantas de batata e, com a adição de Si, o tratamento com deficiência hídrica apresentou maior teor de $\mathrm{Si}$, ou seja, a combinação da aplicação de silicato com deficiência hídrica proporcionou o maior teor de Si nas folhas. A batata é considerada uma planta não acumuladora de Si (Marschner, 1995). Segundo Mitani \& Ma (2005), plantas não acumuladoras, como tomate, por exemplo, possuem menor densidade de transportadores de Si do apoplasto para o simplasto e um defeito nos transportadores de Si das células do córtex para o xilema. Os dados obtidos neste trabalho podem indicar que, com déficit hídrico, esse mecanismo de absorção de Si é alterado. O Si é um elemento abundante no solo, porém sua concentração disponível para as plantas na solução do solo normalmente é baixa (Hattori et al., 2005). Mitani \& Ma (2005) observaram aumento na absorção de Si por plantas de tomate submetidas a maiores concentrações do elemento na solução nutritiva.

A correção do solo com silicato proporcionou maior altura das plantas em relação ao tratamento com calcário (Quadro 6). O corretivo utilizado e a condição hídrica do solo não influenciaram o número de hastes por planta. Quanto ao acamamento, constatou-se em ambas as tensões que a aplicação de silicato proporcionou redução dessa variável, sendo da ordem de 40 e $37 \%$, e com calcário, foi de 63 e $59 \%$, respectivamente, para a menor e maior tensão (Quadro 7). No tratamento com calcário, verificou-se

Quadro 6. Altura, número e acamamento das hastes, número e massa de tubérculos comercializáveis e nãocomercializáveis por planta e concentrações de matéria seca e de Si na matéria seca de tubérculos de batata em função da tensão de água no solo e de corretivos

\begin{tabular}{|c|c|c|c|c|c|c|c|c|c|}
\hline \multirow{2}{*}{$\begin{array}{l}\text { Tratamento } \\
\begin{array}{c}\text { Tensão de água } \\
\text { no solo (T) }\end{array}\end{array}$} & \multirow{2}{*}{$\begin{array}{c}\begin{array}{c}\text { Altura } \\
\text { da }\end{array} \\
\text { haste }\end{array}$} & \multirow{2}{*}{$\begin{array}{l}\text { Número } \\
\text { de haste }\end{array}$} & \multirow{2}{*}{$\begin{array}{c}\text { Acamamento } \\
\text { da hastes }\end{array}$} & \multicolumn{2}{|c|}{$\begin{array}{c}\text { Tubérculo } \\
\text { comercializável }\end{array}$} & \multicolumn{2}{|c|}{$\begin{array}{c}\text { Tubérculo } \\
\text { Não-comercializável }\end{array}$} & \multirow{2}{*}{$\begin{array}{c}\text { Matéria } \\
\text { seca no } \\
\text { tubérculo } \\
\end{array}$} & \multirow{2}{*}{$\begin{array}{c}\text { Teor de } \\
\text { Si no } \\
\text { tubérculo } \\
\end{array}$} \\
\hline & & & & $\mathrm{n}^{\circ}$ planta & $\mathrm{g} / \mathrm{planta}$ & $\mathrm{n}^{\circ}$ planta & g/planta & & \\
\hline $\begin{array}{ll}0,020 & \mathrm{MPa} \\
0,050 & \mathrm{MPa}\end{array}$ & $\begin{array}{l}39,2 \mathrm{a} \\
41,1 \mathrm{a}\end{array}$ & $\begin{array}{l}13.9 \mathrm{a} \\
14.2 \mathrm{a}\end{array}$ & $\begin{array}{l}50,1 \mathrm{a} \\
49,6 \mathrm{a}\end{array}$ & $\begin{array}{l}22,0 \mathrm{a} \\
19,6 \mathrm{a}\end{array}$ & $\begin{array}{l}896,0 \\
783,8\end{array}$ & $\begin{array}{l}10,4 \mathrm{a} \\
10,7 \mathrm{a}\end{array}$ & $\begin{array}{l}45,4 \\
49,6\end{array}$ & $\begin{array}{l}26,1 \mathrm{a} \\
27,1 \mathrm{a}\end{array}$ & $\begin{array}{l}0,25 \\
0,23\end{array}$ \\
\hline \multicolumn{10}{|l|}{ Corretivo (C) } \\
\hline $\begin{array}{l}\text { Calcário } \\
\text { Silicato } \\
\text { Interação T x C }\end{array}$ & $\begin{array}{l}34,4 \mathrm{~b} \\
45,6 \mathrm{a} \\
\mathrm{ns}\end{array}$ & $\begin{array}{c}13.7 \mathrm{a} \\
14.4 \mathrm{a} \\
\mathrm{ns}\end{array}$ & $\begin{array}{l}61,1 \mathrm{a} \\
38,6 \mathrm{~b} \\
*\end{array}$ & $\begin{array}{l}20,7 \mathrm{a} \\
20,9 \mathrm{a} \\
\mathrm{ns}\end{array}$ & $\begin{array}{c}778,5 \\
901,3 \\
*\end{array}$ & $\begin{array}{l}10,3 \mathrm{a} \\
10,8 \mathrm{a} \\
\mathrm{ns}\end{array}$ & $\begin{array}{c}49,9 \\
45,2 \\
*\end{array}$ & $\begin{array}{l}27,2 \mathrm{a} \\
26,1 \mathrm{a} \\
\mathrm{ns}\end{array}$ & $\begin{array}{l}0,22 \\
0,26 \\
*\end{array}$ \\
\hline CV (\%) & 13,7 & 15,0 & 8,9 & 25,9 & 10,2 & 21,9 & 12,5 & 6,5 & 18,6 \\
\hline
\end{tabular}

Médias seguidas de letras distintas na coluna, para cada fator, diferem entre si pelo teste t (DMS) a 5 \%. Interação: ns: não significativo $e^{*}$ : significativo, pelo teste t a $5 \%$. 
que a maior disponibilidade hídrica proporcionou índice de acamamento significativamente maior em relação à maior tensão. A redução no acamamento de hastes, proporcionada pela aplicação de $\mathrm{Si}$, pode estar relacionada com a melhor condição hídrica nas células promovida pelo ajustamento osmótico, o que resultou em células mais túrgidas, beneficiando o alongamento celular e aumentando a resistência mecânica das células. Hattori et al. (2005) verificaram que a aplicação de Si promoveu maior taxa fotossintética, taxa de crescimento e acúmulo de matéria seca em plantas de sorgo sob deficiência hídrica. O acúmulo de Si nas hastes e sua associação com a cutícula, bem como sua polimerização em tecidos do vegetal, podem também ter contribuído para a redução do acamamento das hastes observada neste trabalho, em razão de proporcionar maior resistência mecânica aos tecidos.

Os números de tubérculos comercializáveis e nãocomercializáveis não foram influenciados pelos fatores estudados, contudo a produção de tubérculos por planta, tanto comercializáveis quando não sofreu efeito da interação entre corretivos e tensão de água no solo, ou seja, os fatores tiverem influência na massa e não no número de tubérculos por planta (Quadro 7).

A produção de tubérculos comercializáveis foi maior no tratamento com silicato nas duas tensões estudadas. Quando da utilização de silicato, com menor tensão hídrica, a produção de tubérculos comercializáveis foi

Quadro 7. Acamamento das hastes, massa de tubérculos comercializáveis e não-comercializáveis por planta e teor de Si na matéria seca de tubérculos de batata em função da tensão de água do solo e de corretivos

\begin{tabular}{|c|c|c|c|}
\hline \multirow{2}{*}{\multicolumn{2}{|c|}{$\begin{array}{c}\text { Tensão de água } \\
\text { no solo }\end{array}$}} & \multicolumn{2}{|c|}{ Corretivo } \\
\hline & & Calcário & Silicato \\
\hline & & \multicolumn{2}{|c|}{ Acamamento das hastes, $\%$} \\
\hline 0,020 & $\mathrm{MPa}$ & $63,4 \mathrm{aA}$ & $36,8 \mathrm{aB}$ \\
\hline \multirow[t]{2}{*}{0,050} & $\mathrm{MPa}$ & $58,8 \mathrm{bA}$ & $40,5 \mathrm{aB}$ \\
\hline & & \multicolumn{2}{|c|}{ Tubérculo comercializável, g/planta } \\
\hline 0,020 & $\mathrm{MPa}$ & $819,5 \mathrm{aB}$ & $972,5 \mathrm{aA}$ \\
\hline \multirow[t]{2}{*}{0,050} & $\mathrm{MPa}$ & $737,5 \mathrm{aB}$ & $830,0 \mathrm{bA}$ \\
\hline & & \multicolumn{2}{|c|}{ Tubérculo não-comercializável, g/planta } \\
\hline 0,020 & $\mathrm{MPa}$ & $48,8 \mathrm{aA}$ & $42,1 \mathrm{aB}$ \\
\hline \multirow[t]{2}{*}{0,050} & $\mathrm{MPa}$ & $51,0 \mathrm{aA}$ & $48,3 \mathrm{aA}$ \\
\hline & & \multicolumn{2}{|c|}{ Concentração de Si nos tubérculos, \% } \\
\hline 0,020 & $\mathrm{MPa}$ & $0,22 \mathrm{aB}$ & $0,28 \mathrm{aA}$ \\
\hline 0,050 & $\mathrm{MPa}$ & $0,22 \mathrm{aA}$ & $0,24 \mathrm{aA}$ \\
\hline
\end{tabular}

Médias seguidas de letras distintas, minúsculas nas colunas e maiúsculas nas linhas, diferem entre si pelo teste de t(DMS) a $5 \%$. maior, o que não foi constatado com o uso de calcário (Quadro 7). Quanto à produção de tubérculos nãocomercializáveis, verificou-se que a aplicação de silicato, especialmente com adequada disponibilidade hídrica, proporcionou redução dessa variável, o que comercialmente é uma característica interessante. Esses resultados demonstram que a presença de $\mathrm{Si}$ no solo é benéfica também em condições hídricas adequadas.

A maior absorção de $\mathrm{P}$, proporcionada pelo tratamento com silicato, também pode ter contribuído para o aumento na produção de tubérculos comercializáveis. Resultado semelhante foi obtido por Maciel (1983), que, estudando diferentes fontes de $\mathrm{P}$ na cultura da batata, constatou que o termofosfato foi superior em relação a outras fontes, promovendo maior produtividade de tubérculos, o que pode ser atribuído à menor fixação do $\mathrm{P}$ no solo em função da presença de Si solúvel nesta fonte.

Os benefícios observados na arquitetura das plantas em função da maior disponibilidade de Si no solo parecem ter resultado em maior produção, pois plantas maiores e mais eretas provavelmente produziram maior área foliar e tiveram maior eficiência de interceptação da luz. Esses dois fatores associados permitiram melhor desempenho da planta no tratamento com silicato. Esta hipótese é reforçada pelo fato de o aumento da produção ser devido, principalmente, ao maior peso médio dos tubérculos, e não ao aumento do número (Quadros 6 e 7), ou seja, a maior produção foi resultante do maior enchimento dos tubérculos, em conseqüência de maior produção de fotoassimilados.

A percentagem de matéria seca nos tubérculos não foi influenciada pelos tratamentos (Quadro 6). Com relação ao teor de Si nos tubérculos, observa-se que, na menor tensão $(0,020 \mathrm{MPa})$, a aplicação de silicato proporcionou maiores valores, enquanto na maior tensão $(0,050 \mathrm{MPa})$ não houve diferença entre os corretivos estudados. Esses dados indicam que o Si provavelmente se comporta de maneira semelhante ao Ca em relação à absorção pelos tubérculos, uma vez que os teores de Si nas folhas foram maiores no tratamento com silicato, em relação ao calcário, apenas na maior tensão, indicando que pode não ter havido translocação do elemento para os tubérculos.

\section{CONCLUSÕES}

1. A deficiência hídrica nas tensões de água estudas tem pouca influência na nutrição da batateira, porém reduz a produção de tubérculos comercializáveis.

2. O silicato de $\mathrm{Ca}$ e $\mathrm{Mg}$ proporciona os mesmos níveis de correção do solo e de fornecimento de Ca e $\mathrm{Mg}$ à cultura da batata que o calcário dolomítico, podendo ser utilizado em sua substituição. 
3. A aplicação de Si proporciona maior disponibilidade de P e Si no solo e maior absorção desses elementos pelas plantas de batata, em comparação com o calcário.

4. O fornecimento de Si à cultura da batata, proporciona maior altura de plantas, menor acamamento das hastes e maior produção de tubérculos comercializáveis.

\section{LITERATURA CITADA}

ALCARDE, J.C. Corretivo de acidez do solo: Características e interpretações. São Paulo, Associação Nacional para Difusão de Adubos e Corretivos Agrícolas, 1992. 26p. (Boletim Técnico, 6)

CAMARGO, M.S.; PEREIRA, H.S.; KORNDÖRFER, G.H.; QUEIROZ, A.A. \& REIS, C.B. Soil reaction and absorption of silicon by rice. Sci. Agric., 64:176-180, 2007.

CARVALHO-PUPATTO, J.G.; BÜLL, L.T. \& CRUSCIOL, C.A.C. Atributos químicos do solo, crescimento radicular e produtividade do arroz de acordo com a aplicação de escórias. Pesq. Agropec. Bras., 39:1213-1218, 2004.

COSTA, L. D.; VEDOVE, G.D.; GIANQUINTOI, G.; GIOVANARDI, R. \& PERESSOTTI, A. Yield, water use efficiency and nitrogen uptake in potato: Influence of drought stress. Potato Res., 40:19-34, 1997.

EKANAYAKE, I.J. Estúdios sobre el estres por sequia y necesidades de riego de la papa. Lima, Centro Internacional de la Papa, 1994. 38p. (Guia de investigación CIP 30)

EMPRESA BRASILEIRA DE PESQUISA AGROPECUÁRIA EMBRAPA. Centro Nacional de Pesquisa de Solos. Manual de métodos de análise de solo. 2.ed. Brasília, 1997. $212 p$.

EMPRESA BRASILEIRA DE PESQUISA AGROPECUÁRIA . EMBRAPA. Centro Nacional de Pesquisa de Solos. Sistema brasileiro de classificação dos solos. Brasília, 2006. $412 \mathrm{p}$.

EPSTEIN, E. \& GRANT, W.J. Water stress relation of the potato plant under field conditions. Agron. J., 65:400-404, 1973.

ERDEM, T.; ERDEM, Y.; ORTA, H. \& OKURSOY, H. Wateryield relationships of potato under different irrigation methods and regimens. Sci. Agric., 63:226-231, 2006.

GONG, H.; ZHU, X.; CHEN, K.; WANG, S. \& ZHANG, C. Silicon alleviates oxidative damage of wheat plants in pots under drought. Plant Sci., 169:313-321, 2005.

GREGORY, P.J. \& SIMMONDS, L.P. Water relations and growth of potatoes. In: HARRIS, P.M., ed. The potato crop - The scientific basis for improvement. 2.ed. London, Chapman and Hall, 1992. p.214-246.

GUÉVEL, M.H.; MENZIES, J.G. \& BÉLANGER R.R. Effect of root and foliar applications of soluble silicon on powdery mildew control and growth of wheat plants. Eur. J. Plant Pathol., 118:115-123, 2007.
HATTORI, T.; INANAGA, S.; ARAKI, H.; AN, P.; MORITA, S.; LUXOVÁ, M. \& LUX, A. Application of silicon enhanced drought tolerance in sorghum bicolor. Physiol. Plant., 123:459-466, 2005.

JONES JUNIOR, J.B.; WOLF, B. \& MILL, H.A. Plant analysis handbook. Athens, Micro-macro Publishing, 1991. 213p.

KORNDÖRFER, G.H.; NOLLA, A. \& OLIVEIRA, L.A. Análise de silício: Solo, planta e fertilizante. Uberlândia, GPSiICIAG-UFU, 2004. 39p. (Boletim Técnico, 2)

LIMA FILHO, O.F.; LIMA, M.T.G. \& TSAI, S.M. O silício na agricultura. Inf. Agron., 87:1-7, 1999 (Encarte Técnico)

LOON, C.D. The effect of water stress on potato growth, development and yield. Am. Potato J., 58:51-69, 1981

LOPES, M.S. Relações entre o $\mathrm{pH}$ e a adsorção de fósforo e silício em solos. Porto Alegre, Universidade Federal do Rio Grande do Sul, 1977. 45p. (Tese de Mestrado)

LORENZI, J.O.; MONTEIRO, P.A.; MIRANDA FILHO, H.S. \& RAIJ, B.van. Raízes e tubérculos. In: RAIJ, B.van; CANTARELLA, H.; QUAGGIO, J.A. \& FURLANI, A.M.C., eds. Recomendações de adubação e calagem para o Estado de São Paulo. Campinas, Instituto Agronômico de Campinas, 1997. p.221-229 (Boletim Técnico, 100)

MA, J.F. Role of silicon in enhancing the resistance of plants to biotic and abiotic stresses. Soil Sci. Plant Nutr., 50:11$18,2004$.

MA, J.F. \& YAMAJI, N. Silicon uptake and accumulation in higher plants. Trends Plant Sci., 11:342-397, 2006.

MACIEL, C.A.C. Efeito de diferentes fontes de fósforo na produção de batata. Botucatu, Escola Superior de Agricultura e Ciências, 1983. 7p. (Relatório de Pesquisa)

MALAVOLTA, E.; VITTI, G.C. \& OLIVEIRA, S.A. Avaliação do estado nutricional de plantas: Princípios e aplicações. Piracicaba, Potafos, 1997. 308p.

MARSCHNER, H. Mineral nutrition of higher plants. 2.ed. London, Academic Press, 1995. 889p.

MITANI, N. \& MA, J.F. Uptake system of silicon in different plant species. J. Exper. Bot., 56:1255-1261, 2005.

MIRANDA FILHO, H.S.; GRANJA, N.P \& RAMOS, V.J. Efeito do cálcio na produtividade e qualidade de dois cultivares IAC de batata. I. Produção e classificação. Hort. Bras., 8:53, 1990.

OLIVEIRA, C.A.S. \& VALADÃO, L.T. Manejo da água do solo no cultivo da batata. Brasília, Embrapa Hortaliças, 1997. 8p. (Comunicado Técnico, 3)

PRADO, R.M. \& FERNANDES, F.M. Efeito da escória de siderurgia e calcário na disponibilidade de fósforo de um Latossolo Vermelho-Amarelo cultivado com cana-deaçúcar. Pesq. Agropec. Bras., 36:1199-1204, 2001.

RAIJ, B.van; ANDRADE, J.C.; CANTARELLA, H. \& QUAGGIO, J.A. Análise química para avaliação da fertilidade de solos tropicais. Campinas, Instituto Agronômico de Campinas, 2001. 284p. 
RAMOS, L.A.; NOLLA, A.; KORNDÖRFER, G.H.; PEREIRA, H.S. \& CAMARGO, M.S. Reatividade de corretivos da acidez e condicionadores de solo em colunas de lixiviação. R. Bras. Ci. Solo, 30:849-857, 2006.

RICHARDS, L.A. Methods of measuring moisture tension. Soil Sci., 68:95-112, 1949.

SMYTH, T.J. \& SANCHEZ, P.A. Effects of lime, silicate, and phosphorus applications to an Oxisol on phosphorus sorption and ion retention. Soil Sci. Soc. Am. J., 44:500$505,1980$.
TOPP, G.C.; GALGANOV, Y.T.; BALL, B.C. \& CARTER, M.R. Soil water desorption curves. In: CARTER, M.R., ed. Soil sampling and methods of analysis. Boca Raton, Lewis Publishers, 1993. p.569-579.

VERMAS, T.S. \& MINHAS, R.S. Effect of iron and manganese interaction on paddy yield and iron and manganese nutrition in silicon-treated and untreated soil. Soil Sci., 147:107-115, 1989.

ZHU, Z.; WEI, G.; LI, J.; QIAN Q. \& YUET, J. Silicon alleviates salt stress and increases antioxidant enzymes activity in leaves of salt-stressed cucumber (Cucumis sativus L.). Plant Sci., 167:527-533, 2004 